\title{
Energy consumption and seismic retrofitting interventions in the architectural heritage: building performance simulations of a historical building in Italy
}

\author{
Mariangela De Vita ${ }^{1,}$, Raffaella D’Antonio ${ }^{2}$ and Antonio Mannella ${ }^{1}$, \\ ${ }^{1}$ Italian National Research Council, Construction Technologies Institute, Via Giosuè Carducci 32, \\ 67100 L'Aquila, Italy \\ ${ }^{2}$ DICEAA, University of L'Aquila, Via G. Gronchi 18, 67100 L'Aquila, Italy
}

\begin{abstract}
This study focuses on retrofit interventions that allow a seismic improvement of the Architectural Heritage whose critical aspects are conservation and enhancement of existing buildings. During the last decades, designers and researchers have invested in the technical development of seismic retrofitting interventions with the aim of improving the structural performances in a cost-effective way without sacrificing the aesthetical aspects of valuable buildings. Moreover, recent research on historical masonry provided important references and data on the advantages of these interventions in the Architectural Heritage protection. Despite the technological progress, seismic interventions in terms of environmental performance still represent a critical issue, so it is essential to assess their effects on energetic behaviour. The aim of the research is to evaluate the effects of most used seismic retrofitting interventions on energy performance of a masonry historical buildings. The Authors present and analyse the hypothesis of seismic interventions applied on the masonry of a historical building located in the town of L'Aquila and severely damaged by an earthquake that in 2009 struck Abruzzo County, in Italy. The study includes results of building performance simulations (BPS) of the entire building, carried out with the software "Design Builder", which allows the assessment of the seismic interventions from the environmental point of view on the basis of the variation of energy consumption and the internal comfort.
\end{abstract}

\section{Introduction}

Architectural Heritage in Europe is mainly made up of old buildings [1] constructed using masonry walls. Recent regulations, such as the EU Directive 2010/31 [2] on energy efficiency of buildings, aim to increase performance standards of the envelopes, considering both the single components and the entire building. These regulations have led to a substantial gap in the required energy performance between new buildings and historic

* Corresponding author: devita@itc.cnr.it 
ones. Furthermore, an absence of rules about better compatibility between available retrofit technologies and used materials, highlights the need to investigate and produce new research results that can stimulate and guide both designers and government bodies.

In the last years, several researches studied the theme of seismic retrofit combining it with energy saving [3, 4]. In order to produce a comparison among the most common retrofit interventions used in the restoration of Architectural Heritage, dynamic simulations of entire buildings [5] offer more comprehensive results compared to the evaluation of specific solutions for thermal transmittance reduction - such as thermal, vegetal based, insulating plaster [6]. The Building Performance Simulations (BPS) can be called dynamic as the software changes the boundary condition of the model, according to a weather database for the outside environment and to the inside comfort conditions, for each hour of every day of the year. Furthermore, the simulations offer the possibility of persecuting superb analysis on compatibility, which are crucial during interventions on valuable masonries. To conclude, in the refurbishment and retrofit of historical buildings, the state of the art suggests that combined interventions and multidisciplinary studies represent the best approach, an approach that this research intends to follow and develop.

\section{Case study: E. De Amicis school}

\subsection{The history of the building}

Giovanni da Capestrano, an important friar of the $13^{\text {th }}$ century, commissioned the construction the "S. Salvatore" major hospital, which was completed in 1457. In 1779, when the hospital was transferred to a different location, the building was used as a Medical School until, from the second half of the $17^{\text {th }}$ century, it hosted a military dispensary. In the first years of 1900 the town administration acquired the building transforming it into a public school and it remains so until April 2009, when a strong earthquake badly damaged it. The building has laid unchanged since then, waiting to be restored to its original state.

\subsection{The actual state}

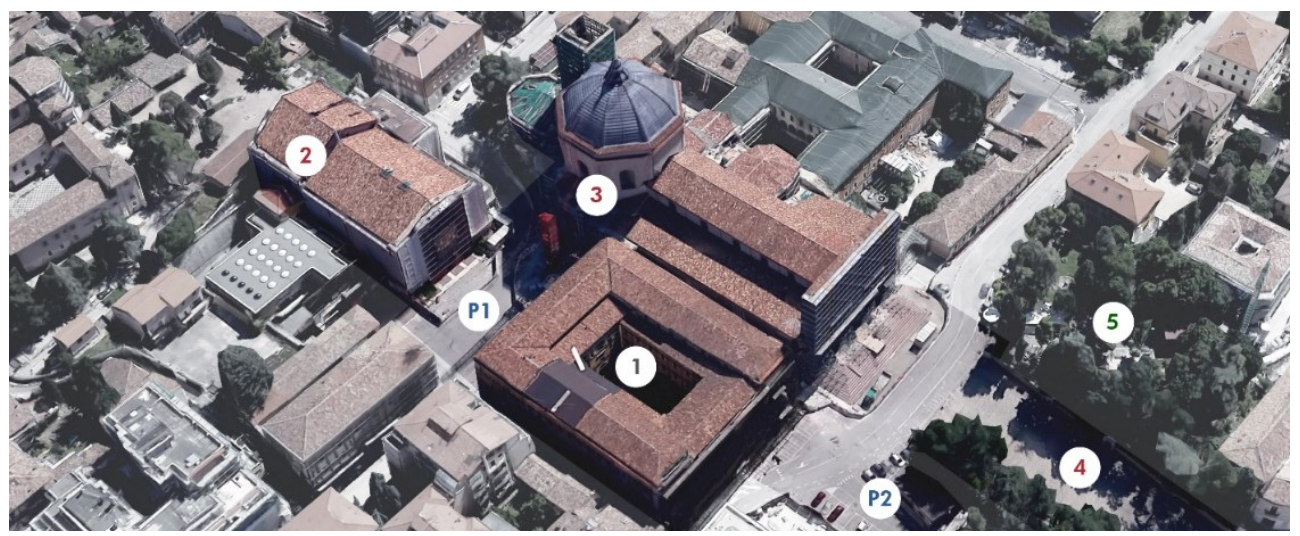

Fig. 1. Axonometric view of the area: 1. "E. De Amicis" school; 2. Municipal theatre; 3. Basilica of S. Bernardino; 4. "S. Bernardino" staircase; 5. Public park; P1. "del Teatro" square; P2. "S.

Bernardino" square. [7]

The rectangular shaped building of the former school is situated next to the Basilica of $\mathrm{S}$. Bernardino and it is surrounded by various important sites (Figure 1). The courtyard is surrounded by a colonnade sustaining a hallway on the first and second floor. On the top of 
the second floor there is an irregular pitched roof, lower in correspondence of where the hallway is.

\section{Retrofit interventions for seismic improvement}

Restoration projects that include seismic improvements use several different types of intervention. Figure 2 illustrates the distribution of the principal interventions carried out on masonry buildings located outside the historical center of L'Aquila after the earthquake $(\mathrm{Mw}=6.3)$ that occurred in the Abruzzi region on the 6 April 2009.

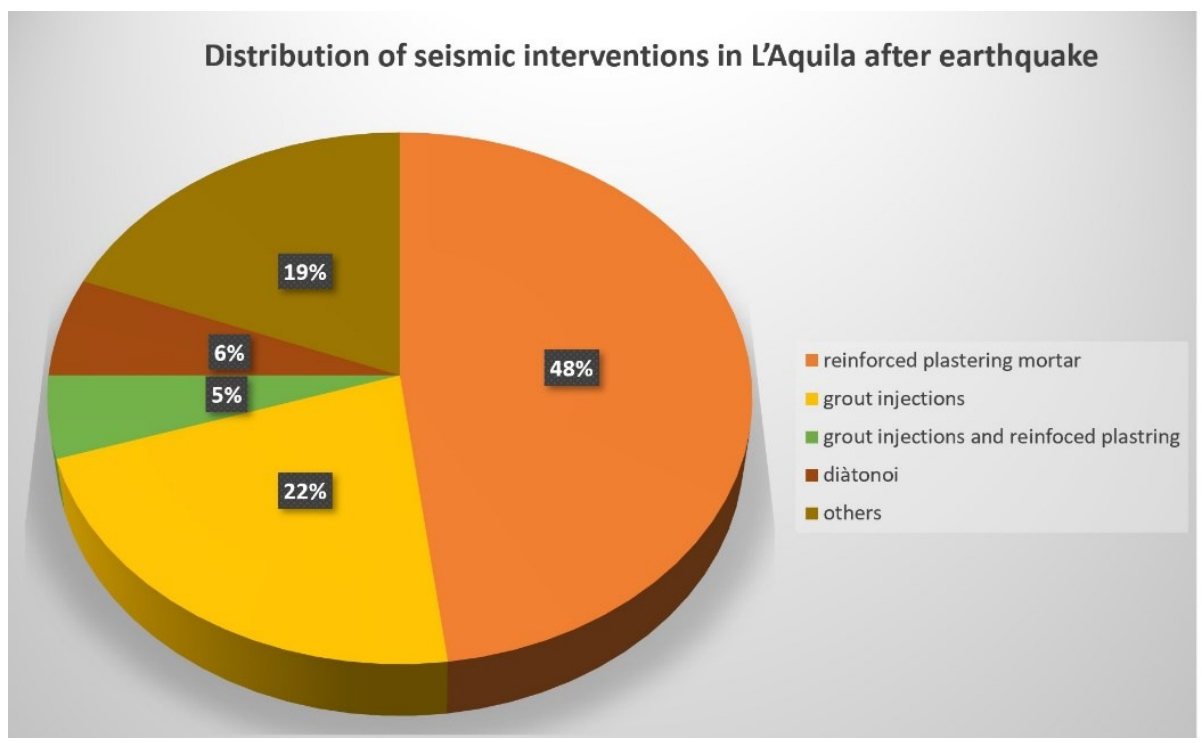

Fig. 2. Seismic improvement interventions most frequently adopted in the reconstruction of L'Aquila

The interventions investigated in this paper are the most commonly used in the seismic retrofit of buildings damaged by earthquakes. The damage in the E. De Amicis school was caused by the poor quality of the masonry, the poor quality of the connections between the masonry panels and the floors and the high inter-storey height. In these cases, seismic retrofit interventions often involve the increase of the mechanical strength and of the ductility of the masonry. Some of the most frequently used masonry consolidation techniques include mortar injections and the facing of masonries with reinforced plaster [4, 8]. The ones adopted in the model described in this paper are shown in Table 1.

Table 1. Definition of the seismic interventions adopted in the model.

\begin{tabular}{|c|l|}
\hline ID & \multicolumn{1}{|c|}{ Description of the intervention } \\
\hline GI1 & $\begin{array}{l}\text { Grout injections and } 2 \mathrm{~cm} \text { of finishing cement plaster } \\
\text { (exterior side) }\end{array}$ \\
\hline GI + RP & $\begin{array}{l}\text { Grout injections }+2 \mathrm{~cm} \text { reinforced plaster and } 1 \mathrm{~cm} \text { of } \\
\text { finishing cement plaster (both sides) }\end{array}$ \\
\hline RP & $\begin{array}{l}2 \mathrm{~cm} \text { reinforced plaster and } 1 \mathrm{~cm} \text { of finishing cement } \\
\text { plaster (both sides) }\end{array}$ \\
\hline
\end{tabular}




\section{The model of the building performance simulation}

The analyses have been carried out using Design Builder software [9]. The main objective of an energy simulation is to compare different seismic retrofit strategies to optimize energy consumption and costs.
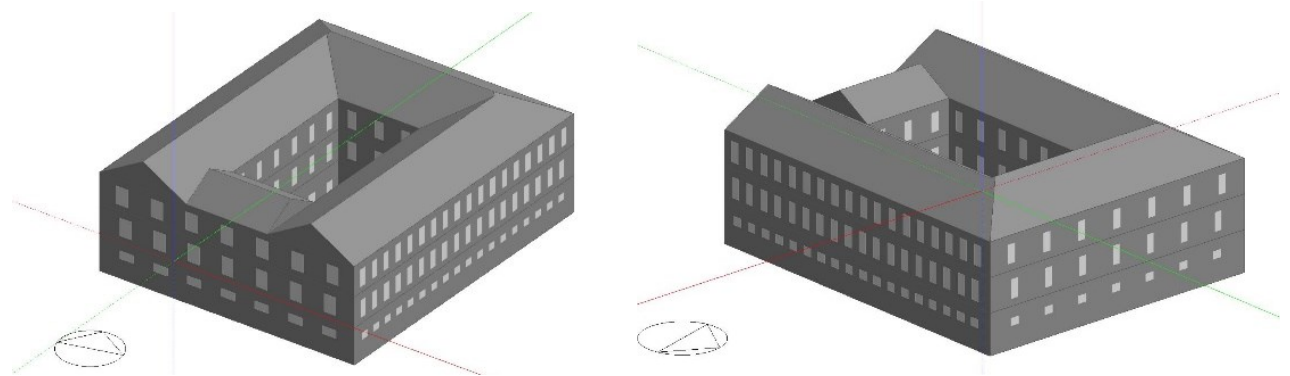

Fig. 3. Axonometric views of the model from the south-east (left) and the north-east (right).

The Location Template refers to the weather data of Campobasso, a city that has a similar climatic condition to the city of L'Aquila, whose weather data is not available in the software library. The Activity was set to "Generic Office Area" for what concerns the building and for the atrium was set to "Standing/walking" with an Occupancy density set to 0.05 people $/ \mathrm{m}^{2}$. For the Openings, the window template was chosen according to the minimum Italian Standards. The Lighting template was automatically generated by the software according to the previously set Activity template. For the HVAC template, radiator heating system and boiler hot water were set up, powered by the natural gas network.

In regard to the Construction template, the pitched roof was chosen from the software gallery and designed, while the exterior walls, which consist of a masonry walls plastered on both sides, were created using data from literature [4] In order to analyze and compare the effect that seismic interventions have on the energy behaviour of the building, the envelope configuration has been simplified and modelled, as it was $760 \mathrm{~mm}$ thick (except for the finishing plaster) for all the three levels (Figure 3); furthermore in the model, both current and project state have been designed assuming the same openings and installations systems: in this way the results of the simulations can be easily checked and referred directly to the reference thickness of the masonry.

In Table 2 are reported the U-Values of the masonry wall after the seismic interventions' adoption. The U-Values correspond to the current state and to the interventions described in Table 1: the values adopted in this research and reported below have been validated by the software in the constructed model.

Table 2. Construction elements characteristics in the model

\begin{tabular}{|c|c|c|c|c|}
\hline $\begin{array}{c}\text { Intervention } \\
\text { type in the } \\
\text { masonry wall }\end{array}$ & $\begin{array}{c}\text { No } \\
\text { intervention }\end{array}$ & GI1 & GI + RP & RP \\
\hline $\begin{array}{c}\mathrm{U}-V a l u e s \\
{\left[\mathrm{~W} / \mathrm{m}^{2} \mathrm{~K}\right]}\end{array}$ & 1.589 & 1.614 & 1.635 & 1.662 \\
\hline
\end{tabular}




\subsection{Simulation results of the four studied scenarios}

A comparison of the results obtained from the building performance simulation enabled various analysis of the functioning of the different retrofit interventions.

The following outputs from the BPS were analyzed and summarized in figure 4 and 5:

- Unitary energy consumption with operating HVAC natural gas system

- $\mathrm{CO}_{2}$ emissions calculated from natural gas employed for the heating system.

Figure 4 and 5 show the increase of the Natural Gas consumption and $\mathrm{CO}_{2}$ production caused by the seismic interventions and ranging from $0,3 \%(\mathrm{GI})$ to $7,1 \%$ (GI+RP). The most relevant results from the building performance simulations show that the percentage increase of $\mathrm{CO}_{2}$ production level is higher in October when the outdoor temperature is higher, but the Solar Radiation has a relevant reduction. It is worthy of note that lower percentage increase in the colder months corresponds to the highest consumption of $\mathrm{CO}_{2}$ in absolute value.

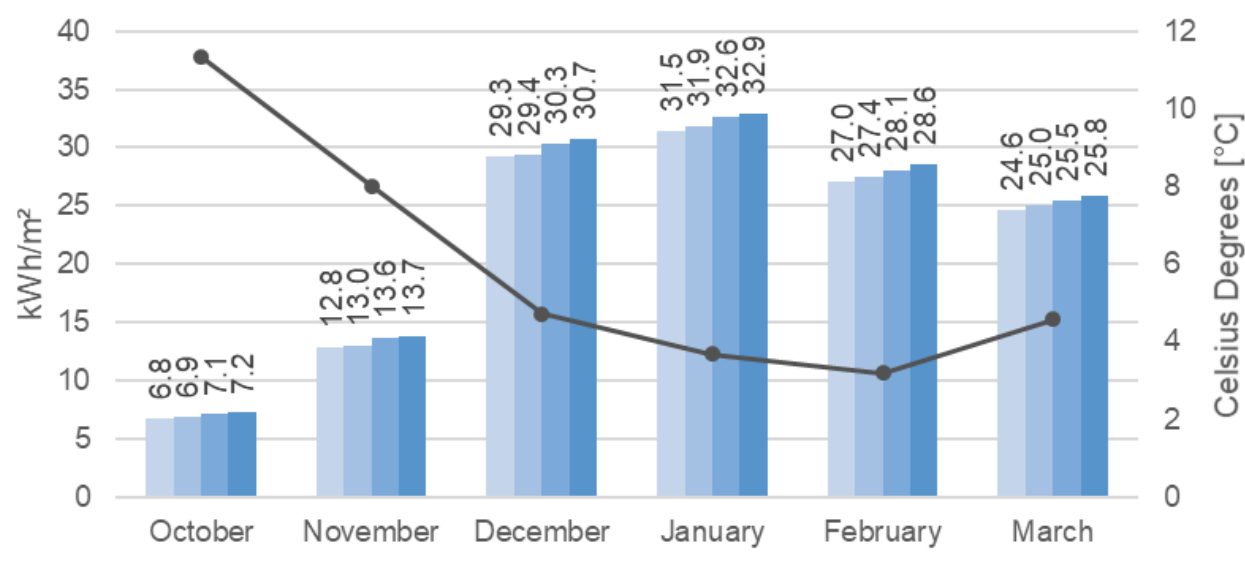

Current State $=\mathrm{Gl} \cong \mathrm{RP} \rightleftharpoons \mathrm{Gl}+\mathrm{RP} \rightarrow$ Dry Bulb Outdoor Temperature

Fig. 4. Unitary energy consumption in the current state and in the project state relate to GI, RP and GI+RP interventions. 


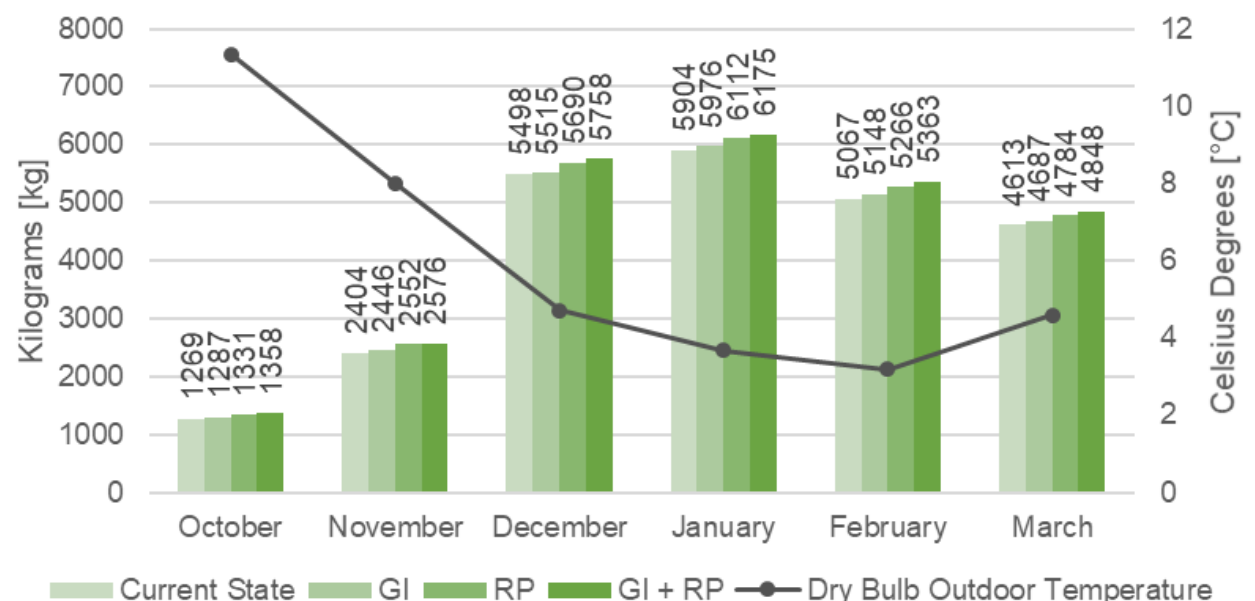

Fig. 5. $\mathrm{CO}_{2}$ production in the current state and in the project state relate to GI, RP and GI+RP interventions.

\section{Discussion and conclusions}

In historic buildings with a load-bearing structure of stone masonry, characterized by a large thermal mass, the variation of the thermal transmittance of the envelope, caused by seismic retrofit interventions, is an aspect that must be analyzed to control the alteration of the environmental performance of those buildings. This article analyses the effects on energy performance of a masonry building with massive envelope in L'Aquila, greatly damaged by the 2009 earthquake, and that whose buildings were object of typical seismic retrofit interventions. Some of the most frequently used techniques have been examined by analysing, for each of them, the resulting effect on energy performances of the building in order to evaluate the variation of $\mathrm{CO}_{2}$ production and Natural Gas consumption. Analysis were carried out with performance simulations under dynamic conditions. This research shows that the adoption of the most used seismic improvement interventions on the historical masonry causes a general, not negligible, worsening in the performance of the building. The analysis carried out carried out on the studied building showed that, although the worst intervention is the combined one (GI+RP), the worsening of the performances is mainly due to the reinforced plaster (RP). This aggravation occurs throughout the year, but the greater energy consumption and $\mathrm{CO}_{2}$ production in absolute value subsists in the winter months. An appropriate evaluation of the used materials and of the employed interventions could allow a lessening of the energy waste whilst respecting the original historical values of the buildings.

Notes: Mariangela De Vita wrote section 1, 4 and 5, constructed the model with Raffaella D'Antonio, designed the outputs and performed the simulations; Raffaella D'Antonio wrote section 2; Antonio Mannella designed the research, wrote section 3 , supervised the results and the paper. 


\section{References}

1. BPIE (Building Performance Institute Europe), Europes Buildings Under the Microscope (2011)

2. Directive 2010/31/EU of the European Parliament and of the Council, Energy Performance of Buildings (2010)

3. F Ascione, F. Ceroni, R.F. De Masi, F. de Rossi, M.R. Pecce, Historical buildings: Multidisciplinary approach to structural / energy diagnosis and performance assessment. Appl. Energy, 185 (2017)

4. M. De Vita, A. Mannella, A. Sabino, A. Marchetti, Seismic Retrofit Measures for Masonry Walls of Historical Buildings, from an Energy Saving Perspective, Sustainability, 10 (4), (2018)

5. R.P. Kramer, M.P.E. Maas, M.H.J. Martens, A.W.M. van Schijndel, H.L. Schellen, Energy conservation in museums using different setpoint strategies: a case study for a state of the art museum using building simulations, Appl. Energy, 158, (2015)

6. J. Zagorskas, E.K. Zavadskas, Z. Turskis, M. Burinskiene, A. Blumberga, D. Blumberga, Thermal insulation alternatives of historic brick buildings in Baltic Sea Region, Energy Build, 78 (2014)

7. R. D'Antonio, Architettura Tessile: Innovazioni E Applicazioni, Tutor Prof. Ing. Pierluigi De Berardinis, C01, Mater Thesis, University of L'Aquila, Italy (2018)

8. A. Borri, R. Sisti, A. Prota, (...), Analisi del danno degli edifici ordinari nel centro storico di Norcia a seguito del sisma del 2016, Proceedings of the $17^{\text {th }}$ Anidis International Congress, Pistoia, Italy, 17-21 September (2017)

9. https://designbuilder.co.uk/ 